\title{
Adaptation or ecological trap? Altered nest-site selection by Reed Parrotbills after an extreme flood
}

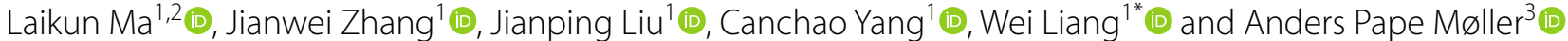

\begin{abstract}
Background: Floods and other extreme events have disastrous effects on wetland breeding birds. However, such events and their consequences are difficult to study due to their rarity and unpredictable occurrence.

Methods: Here we compared nest-sites chosen by Reed Parrotbills (Paradoxornis heudei) during June-August 2016 in Yongnianwa Wetlands, Hebei Province, China, before and after an extreme flooding event.

Results: Twenty-three nests were identified before and 13 new nests after the flood. There was no significant difference in most nest-site characteristics, such as distance from the road, height of the reeds in which nests were built, or nest volume before or after the flood. However, nests after the flood were located significantly higher in the vegetation compared to before the flood (mean \pm SE: $1.17 \pm 0.13 \mathrm{~m}$ vs. $0.75 \pm 0.26 \mathrm{~m}, p<0.01$ ). However, predation rate also increased significantly after the flood (67\% vs. 25\%, $p=0.030$ ).

Conclusions: Our results suggested that Reed Parrotbills demonstrated behavioral plasticity in their nest-site selection. Thus, they appeared to increase the height of their nests in response to the drastically changing water levels in reed wetlands, to reduce the likelihood that their nests would be submerged again by flooding. However, predation rate also increased significantly after the flood, suggesting that the change in nest height to combat the threat of flooding made the nests more susceptible to other threats, such as predation. Animals' response to rare climatic events, such as flooding, may produce ecological traps if they make the animals more susceptible to other kinds of threats they are more likely to continue to encounter.
\end{abstract}

Keywords: Ecological trap, Floods, Nest-site selection, Paradoxornis heudei, Phenotypic plasticity

\section{Background}

Animals rely on habitat selection to survive adverse and fluctuating environmental conditions (Hildén 1965; Cody 1985; Jones 2001). Habitat features are extended phenotypes of living organisms that may affect the probability of survival and reproduction and hence be subject to natural selection. Nest-site selection is an important component of habitat selection. The quality of nest-sites directly affects reproductive success (Macdonald et al. 2016; Maisey et al. 2016). Nest-site selection is affected by many

\footnotetext{
*Correspondence: liangwei@hainnu.edu.cn

${ }^{1}$ Ministry of Education Key Laboratory for Ecology of Tropical Islands,

College of Life Sciences, Hainan Normal University, 571158 Haikou, China

Full list of author information is available at the end of the article
}

biotic and abiotic factors among which nest predation is a primary selective force (Martin 1993; Chalfoun et al. 2002; Fu et al. 2016). In addition, climate, competition, food sources, human interference, parasitism risk, and others can all influence nest-site selection by birds (Martin 1995; Cuervo 2004; Jakubas 2005; Soler 2014; Maisey et al. 2016). In their selection of nest-site, birds may minimize environmental risk factors to ensure a safe, hidden, and suitable environment for reproduction (Cancellieri and Murphy 2014; Jiang et al. 2017).

Recently, both frequency and scale of extreme weather events have increased, greatly increasing the risk of mortality and reproductive failure (Møller 2011; Moreno and Møller 2011). Natural disasters such as heat waves, droughts, blizzards, hurricanes, storms, and floods 
greatly decrease viability of animals, and may seriously threaten bird populations (Demongin et al. 2010; Chambers et al. 2011; Jenouvrier 2013). For example, in 2003, heat waves in parts of Europe caused major declines in bird populations (Jiguet et al. 2006). In years with warm weather, most southern animals, including insects and birds, tend to thrive and breed further north (Jiguet et al. 2006; Cuervo and Møller 2013). A nearly 70-year study of Barn Owls (Tyto alba) discovered that in extremely cold years, when extended periods of snow-cover reduced food supply, the survival rate among adult and sub-adult Barn Owls plummeted (Altwegg et al. 2006).

Unpredictable flooding during bird breeding season would devastate all the offspring due to a lack of escape capacity. For example, flash flooding in the lower Mississippi River destroyed all interior Least Tern (Sternula albifrons) eggs and young in 1993 (Dugger et al. 2002). Likewise, the risk of flooding caused by rising sea levels due to global warming seriously threatens reproduction in wetland shorebirds. Flooding due to high tide triggered by tidal variation and storm was the main factor of breeding failure in birds in coastal wetlands (Marshall and Reinert 1990; Sidle et al. 1992; Bayard and Elphick 2011). Birds should assess all the factors such as flooding, predation, food and so on to ensure maximum fitness. For example, Hunter et al. (2016) showed that Seaside Sparrows (Ammodramus maritimus) could trade the survival risk of flooding against that of predation by managing their nest site selection in relation to the predictability of a threat (see also Greenberg et al. 2006; Anteau et al. 2012; Hunter 2017). However, sometimes the changes that animals made in response to rare climatic events such as flooding will make them more susceptible to other threats. In other words, animals will consider high quality sites to be of low quality, or visa versa, because of the climatic event, since they may not have accurate information on its rarity, producing an "ecological trap" (Donovan and Thompson 2001; Battin 2004; Martijn et al. 2010). Our understanding of the importance of such rare events is however as yet inadequate, partially because the events' very unpredictability makes it difficult to collect data about them (Martijn et al. 2010).

On 19 July 2016, Yongnian County in Hebei Province, China, suffered rare heavy rainfall with an average rainfall of more than $400 \mathrm{~mm}$ which was the only occurrence in decades and led to the worst flash flood event in recent 20 years (http://www.hbsw.net/xinwengonggao/sheng neixinwen/2016-07-21/21566.html). A storm caused local water systems, like the Zhang River watershed, to flood into the Yongnianwa Wetland, so that water levels there increased by an average of $1 \mathrm{~m}$ or more. Water levels did not return to normal until 25 July 2016 . Using this rare weather event, we studied nest-site selection by Reed
Parrotbills (Paradoxornis heudei) (Fig. 1a) that breed in reeds in the Yongnianwa Wetlands. We focused on how extreme weather events, like flooding, can affect reproductive success, and how birds respond to such unfavorable conditions when trading reproductive success due to nest site selection against nest predation. We hypothesize that flooding will greatly reduce reproductive success of Reed Parrotbills, and that the birds will alter their nest selection strategy if they start to breed again. However, this change in behavior might make the birds more susceptible to other threats, such as nest predation.

\section{Methods \\ Study area}

The research area is Yongnianwa Wetland, located within Yongnian County in Hebei Province, China $\left(36^{\circ} 40^{\prime} 60^{\prime \prime}-36^{\circ} 41^{\prime} 06^{\prime \prime} \mathrm{N}, 114^{\circ} 41^{\prime} 15^{\prime \prime}-114^{\circ} 45^{\prime} 00^{\prime \prime} \mathrm{E}, 40.3 \mathrm{~m}\right.$ a.s.l.). Yongnianwa is a natural wetland that belongs to the alluvial plain area of the Fuyang River, a tributary to the Hai River Basin. It is located at the convergence of the Fuyang River and the Zhang River watersheds. The water system in Yongnianwa Wetland, which remains wet year-round, is well-developed with many tributaries. The wetland is also the lowest elevation point in Yongnian County with a warm, temperate, semi-humid, and continental monsoon climate with four distinct seasons (Ma et al. 2018). Common plant species in the wetland include Reeds (Phragmites australis) and Broad Leaf Cattails (Typha latifolia).

\section{Field data collection}

Field work was carried out during the breeding season of the Reed Parrotbill, during June-August 2016. We searched systematically for nests of Reed Parrotbills in the study area, and the locations of nests were marked using a GPS followed by measurements of a range of nest-related landscape, micro-habitat, and nest structure parameters (see below, Table 1; Li et al. 2016). We revisited nests to determine the ultimate fate of nests every 1-3 days. All nests were measured when they were still active. Nest fate with respect to flooding was determined from obvious traces of flooding with dead eggs or nestlings in the nests, which were active 1 or 2 days before the flood. Nest fate with respect to predation was determined from the disappearance of nest contents (e.g., clutch or nestlings) prior to the presumed date of fledging (e.g., less than 10 days, also see Li et al. 2016; Macdonald et al. 2016).

The following nest landscape parameters related to nest accessibility influencing predation risk were recorded for each nest-site: (1) distance to road: the distance between the nest-site and the nearest road with human activity; (2) distance to reed edge: the distance from the nest-site 


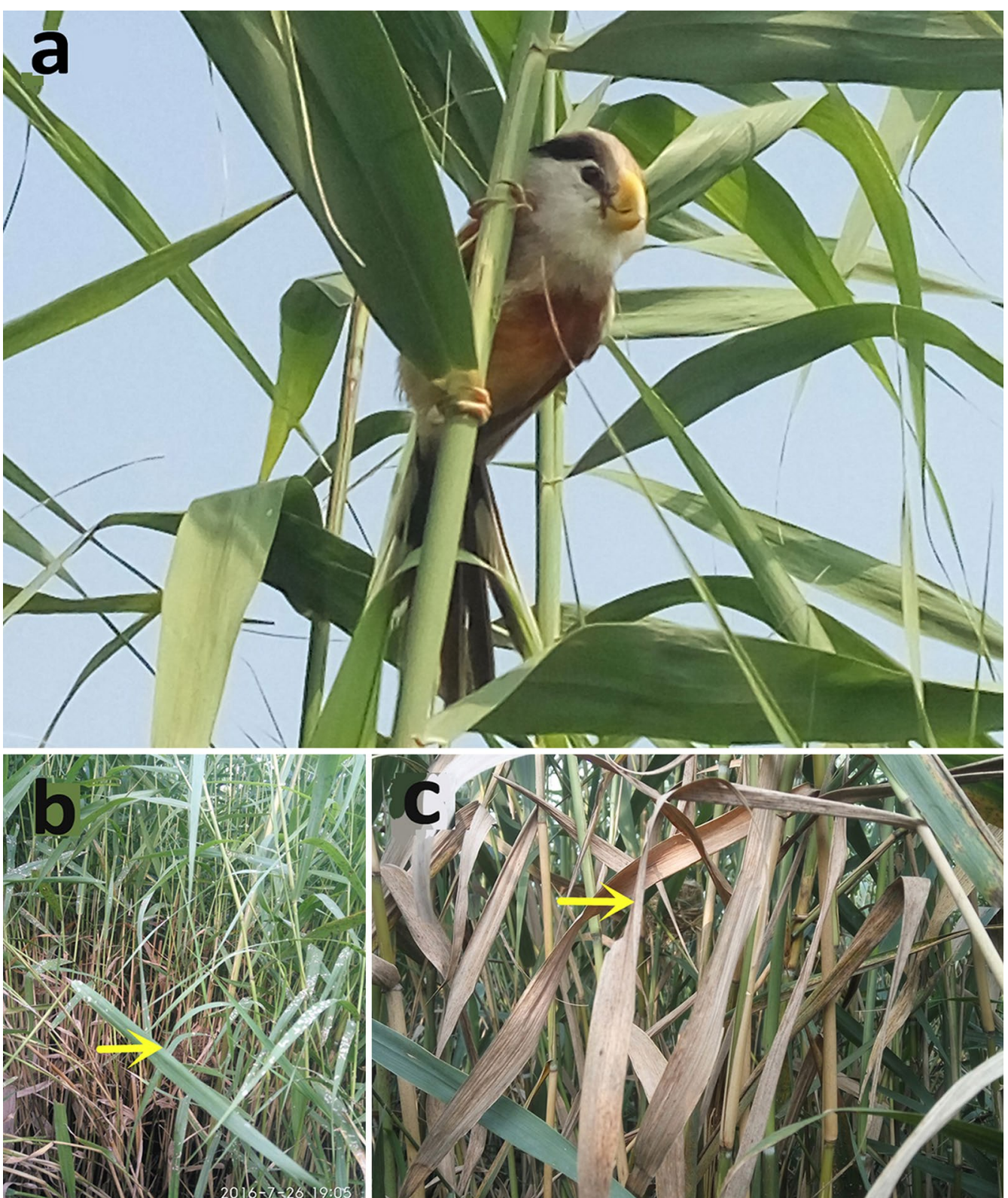

Fig. 1 The Reed Parrotbill (Paradoxornis heudei) (a) and its nest in the reed habitat before (b) and after a flooding event (c)

to the nearest reed edge; (3) distance to water edge: the distance from the nest-site to the nearest body of water; and (4) distance to perch: distance from the nest-site to the nearest perch that a predator could use to observe the nest.

The following parameters (1)-(6) may influence the degree of concealment and predation risk of nests, while (7)-(9) which in turn may influence the risk of flooding related to the micro-habitat of each nest-site which we recorded: (1) vegetation cover: the degree of canopy cover $10 \mathrm{~cm}$ above the nest; (2) nest height: the distance between the nest and the ground/water surface; (3) reed height above nest (m): the height of the reeds above the nest; (4) water depth: the average water depth directly below the nest; (5) number of reed stems: the number of reed stems within a $1 \mathrm{~m} \times 1 \mathrm{~m}$ square sample centered at the nest; (6) height of reed: the height of the nesting reeds in a $1 \mathrm{~m} \times 1 \mathrm{~m}$ square sample centered at the nest. That is, the natural height of the reeds measured from the water surface; (7) number of reed stems for nests: the number of reeds that supported each nest; (8) height of the flood surface: 
Table 1 Comparison of Reed Parrotbill nest-site characteristics before and after a flooding event

\begin{tabular}{|c|c|c|c|c|c|c|c|c|}
\hline & Variable & Before flood & $n$ & After flood & $n$ & Statistics & df & $p$ \\
\hline \multirow[t]{4}{*}{ Nest landscape } & Distance to road (m) & $24.44 \pm 12.05$ & 18 & $22.46 \pm 7.96$ & 13 & $0.516^{1}$ & 29 & 0.610 \\
\hline & Distance to reed edge (m) & $11.39 \pm 7.82$ & 18 & $9.92 \pm 6.78$ & 13 & $0.544^{1}$ & 29 & 0.591 \\
\hline & Distance to water edge (m) & $13.28 \pm 10.59$ & 18 & $12.31 \pm 11.08$ & 13 & $0.247^{1}$ & 29 & 0.807 \\
\hline & Distance to perch (m) & $31.72 \pm 14.96$ & 18 & $36.54 \pm 21.87$ & 13 & $-0.686^{2}$ & 19.88 & 0.500 \\
\hline \multirow[t]{7}{*}{ Nest-site micro-habitat } & Vegetation cover (\%) & $15.59 \pm 18.28$ & 17 & $26.92 \pm 18.99$ & 13 & $-1.655^{1}$ & 28 & 0.109 \\
\hline & Nest height (m) & $0.76 \pm 0.26$ & 18 & $1.17 \pm 0.13$ & 13 & $-5.852^{2}$ & 26.69 & $<0.001^{* *}$ \\
\hline & Reed height above nest (m) & $1.41 \pm 0.29$ & 18 & $1.07 \pm 0.39$ & 11 & $2.649^{1}$ & 27 & $0.013^{*}$ \\
\hline & Water depth (m) & $0.22 \pm 0.18$ & 12 & $0.18 \pm 0.13$ & 13 & $0.787^{1}$ & 23 & 0.440 \\
\hline & Number of reed stem & $251 \pm 55.82$ & 16 & $231.69 \pm 97.77$ & 13 & $-0.374^{3}$ & - & 0.709 \\
\hline & Height of reed $(\mathrm{m})$ & $2.16 \pm 0.20$ & 18 & $2.26 \pm 0.38$ & 11 & $-0.872^{1}$ & 27 & 0.391 \\
\hline & Number of reed stem for nest & $5.06 \pm 1.39$ & 16 & $4.33 \pm 0.89$ & 12 & $-1.506^{3}$ & - & 0.132 \\
\hline \multirow[t]{6}{*}{ Nest characteristics } & Nest diameter $(\mathrm{cm})$ & $8.15 \pm 1.26$ & 17 & $7.96 \pm 0.96$ & 12 & $-0.474^{3}$ & - & 0.635 \\
\hline & Nest depth (cm) & $8.76 \pm 1.58$ & 17 & $9.88 \pm 1.00$ & 12 & $-2.140^{1}$ & 27 & $0.042^{*}$ \\
\hline & Nest volume $\left(\mathrm{cm}^{3}\right)$ & $322.13 \pm 172.28$ & 17 & $335.66 \pm 107.80$ & 12 & $-0.754^{3}$ & - & 0.451 \\
\hline & Nest cup diameter (cm) & $5.38 \pm 0.52$ & 17 & $5.17 \pm 0.49$ & 12 & $-1.157^{3}$ & - & 0.247 \\
\hline & Nest cup depth $(\mathrm{cm})$ & $4.82 \pm 0.53$ & 17 & $5.42 \pm 0.56$ & 12 & $-2.636^{3}$ & - & $0.008^{* *}$ \\
\hline & Nest cup volume $\left(\mathrm{cm}^{3}\right)$ & $73.89 \pm 16.82$ & 17 & $76.64 \pm 19.30$ & 12 & $-0.445^{3}$ & - & 0.656 \\
\hline
\end{tabular}

Values are mean $\pm S D$

1 Student's $t$ test

2 Welch's $t$ test

${ }^{3}$ Mann-Whitney $U$ test

${ }^{*} p<0.05 ;{ }^{* *} p<0.01$

after the recession of flooding water, the distance between the land and the highest traces of duckweed left in the reeds by the flood was used to estimate the maximum height of flood water; and (9) absolute height of the nest: the distance between the ground surface and the nest (nest height + water depth).

The following parameters that may influence nest resistance to poor weather like heavy rain, wild wind and flood may depend on the structure of each nest that we recorded: (1) nest diameter: the external diameter of the top of the nest; (2) nest depth: the vertical distance between the top and bottom of the nest; (3) nest volume:

$$
\text { nest volume }=4 / 3 \pi \times a^{2} \times b \times X
$$

where $a$ is the minor axis of the nest, $b$ is the major axis of the nest, and $X$ is the proportion of a sphere filled by a nest, $X=1 / 2$ for cup-shaped nests (Palomino et al. 1998); (4) nest cup diameter: the inner diameter of the top of the nest; (5) nest cup depth: the depth of the internal cup of the nest; and (6) nest cup volume: referring to nest volume. All nests were measured when they were still active. We measured and compared nest dimensions before and after the flood because we cannot exclude the possibility that Reed Parrotbills modified their nest sizes as an adaptation to flooding.

\section{Data analysis}

SPSS 16.0 statistical software was used for all statistical analyses. Student's $t$ test, Welch's $t$ test or Mann-Whitney $U$ test was used to compare differences in Reed Parrotbill nest-site variables before and after the flood. Variables that reached statistical significance were used in a binary logistic regression model with forward stepwise procedure to determine key predictors of predation. The level of statistical significance was set to 0.05 .

\section{Results}

We found a total of 36 Reed Parrotbill nests during the whole breeding season. Twenty-three nests were found before the flood and detailed measurements were taken at 18 of these nest-sites (Fig. 1b). The final fate of 20 nests was determined with a reproductive failure rate estimated to $85 \%$ (17 out of 20). After the flood, a total of 13 newly-built nests were discovered (Fig. 1c). Nest-site data were measured after eggs were laid and the final fate of 12 of these 13 nests was determined with a reproduction failure rate of $100 \%$.

Among 20 nests constructed before the flood, the major cause of reproductive failure $(45 \%, 9$ out of 20$)$ was flooding, followed by nest predation (25\%, 5 out of 20$)$. After the flood, the primary cause of reproductive failure 
was predation (67\%, 8 out of 12$)$, which increased significantly after the flood (Fisher's exact test, $p=0.030$ ).

Flooding caused the water level in the study area to rise by on average $1 \mathrm{~m}$. The absolute nest height (above ground) before the flood was $1.02 \pm 0.30 \mathrm{~m}$ ( $n=12$ nests), which was generally lower than the height of flooding of $1.21 \pm 0.19 \mathrm{~m}$ ( $n=22$ nests). When the flood occurred, nine nests contained eggs, hatchlings, or fledglings. After the flood, all these nests had been submerged with a resulting reproduction failure. The absolute nest height after the flood was above the high-water mark during the flood (1.35 $\pm 0.12 \mathrm{~m}, n=13$ ) (Fig. 2).

When comparing nest-site parameters $(n=31)$ before and after the flood, we found that nest height, nest depth and nest cup depth increased higher and reed height above nest decreased significantly after the flood (Table 1). However, logistic regression showed that only nest height entered the model as key predictor (Wald Chi square $=7.366, d f=1, p=0.007$ ).

\section{Discussion}

Recent climate change has resulted in an increased frequency of extreme weather events that have had extreme negative impacts on reproductive success in a diverse array of species. Whether animals are able to cope with such dramatic change remains to be determined. Here we report information on nest site selection, reproductive success and nest size in a wetland passerine bird during a flood, but also the subsequent phenotypic response to this flood.

Nine nests at the hatching or brooding stages before the flood were all destroyed by the flood. Among these,

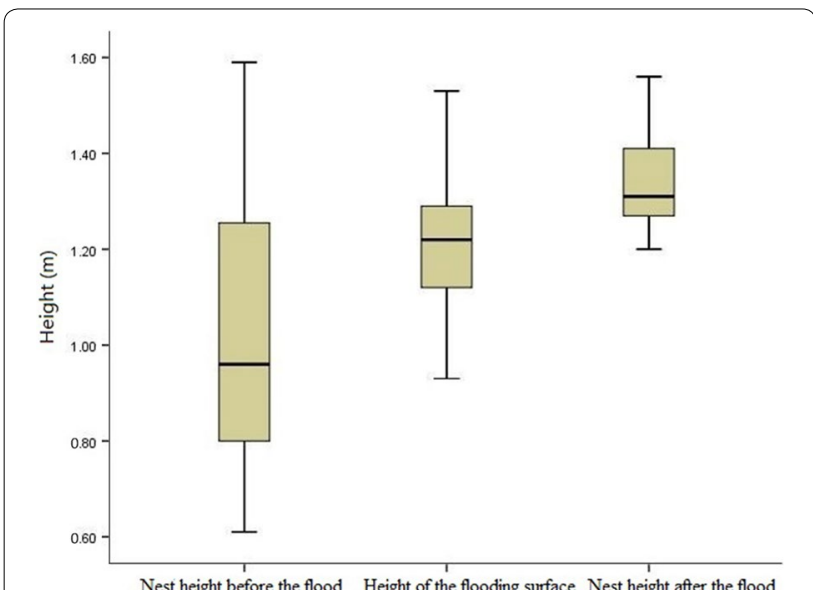

Fig. 2 Nest height of Reed Parrotbills before and after a flooding event and the height of flooding. Shown is nest height above ground level before the flood, height of the flooding level above ground and nest height above ground after the flood. Box plots show means, SD and extreme values seven nests showed clear traces of submersion by floodwater and a few nests had abandoned eggs and/or dead fledglings, indicating that the flood greatly decreased reproductive success of the Reed Parrotbill. However, we observed a significant increase in the height of nests after the flood. This suggests that the Reed Parrotbill demonstrated behavioral flexibility in nest-site selection (see also Hunter et al. 2016), and that it was able to respond to environmental changes brought about by the flood. By increasing nest height, the birds decreased the likelihood that their nests would be submerged again. However, we acknowledge that this study was done in a single season (June-August 2016), and so we do not know whether birds in general or usually build their nests higher above the ground later in the breeding season. If that was the case, such a change in nest building behavior could still reflect selection due to more heavy rains later during the summer.

Previous research has shown that Reed Parrotbills prefer to build their nests in reeds of medium height $(1.5-2.5 \mathrm{~m})$, especially in the lower half of the reeds, which may be a way to reduce nest predation risk (Piper and Catterall 2004; Li et al. 2015). In this study, the height of reeds in which Reed Parrotbills built their nests both before and after flooding was similar to those observed in previous studies. Furthermore, before the flood, nests of Reed Parrotbills were located at approximately $1 / 3$ of the reed height. This behavior is expected to reduce nest predation risk, and we did indeed see a lower rate of nest predation before the flood. However, as our study was done in a single season, we do not know whether nest predation in general or usually increases during the season. Even if that was the case, such a change in nest building behavior could still reflect selection due to more heavy rains later during the summer.

Nest predation is a major cause of reproductive failure among birds, in addition to a major factor influencing nest-site selection (Martin 1995; Macdonald et al. 2016). Furthermore, predation pressure can force birds to adjust the height at which they build their nests to improve their reproductive success. For example, the Oahu Elepaio (Chasiempis ibidis) is an endangered bird endemic to the Hawaiian archipelago. A 16-year continuous study of the height of their nests discovered a $50 \%$ increase in nest height (from 7.9 to $12 \mathrm{~m}$ ) at the same time as reproductive success increased accordingly (Vanderwerf 2012). This was mainly due to the introduction of Black Rats (Rattus rattus) to the islands. Predation pressure from Black Rats forced birds to change their nest-building behavior by increasing nest height (Vanderwerf 2012). Birds breeding in coastal wetlands can maintain stable reproduction depending on rapid and repeated re-nesting in response to nest 
flooding caused by tidal variation (Marshall and Reinert 1990). Larger nests tend to be built at sites closer to water for preventing flooding (Cuervo 2004). Such phenotypic plasticity can be considered an adaptive response widely used by birds to adjust their behavior to environmental conditions (Via et al. 1995; Ghalambor et al. 2007). In the present study, Reed Parrotbills increased the height of their nests significantly, which is indicative of an ability to adapt to changes in the external environment. An increase in nest height reduces the risk of submersion by floodwaters, and the shift in nest-site selection was likely a consequence of the preceding flooding event. Unfortunately, due to the rarity and unpredictable occurrence of flooding, within the season of 2016, there were no controls with which to compare, i.e., nests in areas with no flooding.

Extreme weather events, like floods, can have devastating effects on reproduction of birds. In 1993, flash flooding in the lower reaches of the Mississippi River destroyed all eggs and young birds in an interior Least Tern (Sterna albifrons) population (Dugger et al. 2002). Selection pressure due to severe weather may force birds to adjust their nest-site selection. For example, Laughing Gulls (Larus atricilla) have been shown to choose higher sites for building their nests, or to build taller nests, to reduce the risk of submersion by tidal flooding (Shisler and Colony 1980).

Birds are able to evaluate differences in many environmental factors in order to choose safe, suitable nest-site micro-habitats that provide prime conditions for incubation and brooding (Hansell 2000). Adequate nest-site selection can reduce reproductive investment by adult birds and improve the viability of both parents and offspring (Horvath 1964; Maisey et al. 2016). In spite of this, some studies have shown that adaptive behavior sometimes is insufficient for coping with changes in the external environment, and that a lack of accurate assessment of changes in the external environment can lead to an ecological trap (Donovan and Thompson 2001; Battin 2004; Yang et al. 2014). The cues provided birds by the environment do not always accurately reflect habitat quality. Therefore, behavioral selections that birds make based on such cues can lead to a decrease in their viability (Robertson and Hutto 2006; Yang et al. 2014). Seaside salt marshes, for example, are rich in food supply and have sparse vegetation in which predators may hide, making them attractive for many types of birds for building their nests and reproduction. However, they are also very easily flooded by rising tides that can overturn nests (Martijn et al. 2010). In addition, reproductive costs may be much larger when a previously suitable habitat experiences a sudden change (like a flood or hurricane) (Mérő et al. 2015).
When animals have experienced some threat to their survival/reproduction, they will usually adjust to that. Where they can make mistakes is in judging the probability of that threat reappearing. This demonstrates how rare climatic threats (which may be increased by climate change) could have outsized effects on wildlife: they may make animals make drastic changes in their strategies, which would then have unintended consequences. In the present study, nest predation rate increased significantly after the flood, which may be caused by many factors. One possible explanation was that the increase in nest height reduced the height of reeds above the nests, resulting in lower overall vegetation cover, which led to an increase in visibility and vulnerability of nests to avian predators (Hatchwell et al. 1999; Piper and Catterall 2004). Higher nest predation rate observed after the flood is consistent with the nest exposure hypothesis proposed by Martin (1993). The second possible explanation was that there was no change in predation risk before and after the flood, but the total number of occupied nests was reduced after the flood, resulting in an increased probability of predation, linked to less risk dilution from a smaller total number of nests. Although the reduction in the number of nests would increase the difficulty of finding nests for predators, the availability of food for Reed Parrotbills also decreased after the flood. Parent birds pay higher costs more as a higher frequency of foraging. Thus, the probability of nests being discovered and the risk of predation would be increased by frequent activities and higher nest sites (Martin et al. 2000). The third possible explanation was that nest predation after flooding increased due to a reduction in the amount of available food after the flood. Extreme events such as flooding may cause large ecological disruptions across trophic levels. For example, food availability for local predators may become depleted. Thus, predators may shift their main focus towards different available food sources ("prey switch", see Murdoch 1969; Allen 1988). Therefore, increased predation could reflect increased predator effort, or possibly a combination of increased predator effort and more exposed nests. However, the type and number of local predators and the specific species of predators that depredated the nests remain to be determined.

\section{Conclusions}

This study showed that Reed Parrotbills increased the height of their nests after the flood, probably to reduce the risk of being flooded again. However, reproductive success did not increase. Instead, an increase in the height of the nest after the flood led to an increase in the risk of nest predation. This suggests that response to this rare event may have been ultimately non-adaptive, as it 
may have increased exposure to other threats. Increases in rare climatic catastrophes associated with climate change may therefore have outsized effects on wildlife, from both the immediate effect and from a more delayed effect, caused by non-adaptive responses by the animals.

\section{Authors' contributions}

WL conceived and designed the experiments. LM, JZ and JL conducted the field work. CY and LM performed the data analysis. LM wrote the early draft, WL and APM revised and improved the manuscript. All authors read and approved the final manuscript.

\section{Author details \\ ${ }^{1}$ Ministry of Education Key Laboratory for Ecology of Tropical Islands, College of Life Sciences, Hainan Normal University, 571158 Haikou, China. ${ }^{2}$ Depart- ment of Biology and Food Science, Hebei Normal University for Nationali- ties, 067000 Chengde, China. ${ }^{3}$ Ecologie Systématique Evolution, Université Paris-Sud, CNRS, AgroParisTech, Université Paris-Saclay, F-91405 Orsay Cedex, France.}

\section{Acknowledgements}

We are grateful to Nils Chr. Stenseth and two anonymous reviewers for providing constructive and valuable comments that significantly improved the quality of the manuscript. We thank the Forestry Bureau of Yongnian County, Hebei Province, China, for permission to undertake this study. We are grateful to Bo Zhou and Xiaodong Rao for their assistance with fieldwork.

\section{Competing interests}

The authors declare that they have no competing interests. The funders had no role in study design, data collection and analysis, decision to publish, or preparation of the manuscript.

\section{Availability of data and materials}

The datasets used in the present study are available from the corresponding author on reasonable request.

\section{Consent for publication}

\section{Not applicable.}

\section{Ethics approval and consent to participate}

The experiments comply with the current laws of China. Experimental procedures were in agreement with the Animal Research Ethics Committee of Hainan Provincial Education Centre for Ecology and Environment, Hainan Normal University (permit no. HNECEE-2012-003).

\section{Funding}

This work was supported by the National Natural Science Foundation of China (Nos. 31672303 to CY, 31472013 and 31772453 to WL).

Received: 20 June 2018 Accepted: 7 January 2019

Published online: 11 January 2019

\section{References}

Allen JA. Frequency-dependent selection by predators. Philos Trans R Soc B. 1988;319:485-503.

Altwegg R, Roulin A, Kestenholz M, Jenni L. Demographic effects of extreme winter weather in the barn owl. Oecologia. 2006;149:44-51.

Anteau MJ, Shaffer TL, Sherfy MH, Sovada MA, Stacker JH, Stucker JH. Nest survival of piping plovers at a dynamic reservoir indicates an ecological trap for a threatened population. Oecologia. 2012;170:1167-79.

Battin J. When good animals love bad habitats: ecological traps and the conservation of animal populations. Conserv Biol. 2004;18:1482-91.

Bayard TS, Elphick CS. Planning for sea-level rise: quantifying patterns of saltmarsh sparrow (Ammodramus caudacutus) nest flooding under current sea-level conditions. Auk. 2011;128:393-403.
Cancellieri S, Murphy MT. Experimental analysis of nest-site choice and its relationship to nest success in an open-cup-nesting passerine. Auk. 2014;131:539-48.

Chalfoun AD, Thompson FR, Ratnaswamy MJ. Nest predation and fragmentation: a review and meta-analysis. Conserv Biol. 2002;16:306-18.

Chambers LE, Devney CA, Congdon BC, Dunlop N, Woehler EJ, Dann P. Observed and predicted effects of climate on Australian seabirds. Emu. 2011;111:235-51.

Cody ML. Habitat selection in birds. Orlando: Academic Press; 1985.

Cuervo JJ. Nest-site selection and characteristics in a mixed-species colony of avocets Recurvirostra avosetta and black-winged stilts Himantopus himantopus. Bird Study. 2004,51:20-4.

Cuervo JJ, Møller AP. Temporal variation in population size of European bird species: effects of latitude and marginality of distribution. PLOS ONE. 2013;8:e77654

Demongin L, Poisbleau M, Strange I, Quillfeldt P. Effects of severe rains on the mortality of southern rockhopper penguin (Eudyptes chrysocome) chicks and its impact on breeding success. Ornitol Neotrop. 2010;21:439-43.

Donovan TM, Thompson FR. Modeling the ecological trap hypothesis: a habitat and demographic analysis for migrant songbirds. Ecol Appl. 2001;11:871-82.

Dugger KM, Ryan MR, Galat DL, Renken RB, Smith JW. Reproductive success of the interior least tern (Sterna antillarum) in relation to hydrology on the Lower Mississippi River. River Res Appl. 2002;18:97-105.

Fu Y, Chen B, Dowell SD, Zhang Z. Nest predators, nest-site selection and nest success of the Emei Shan Liocichla (Liocichla omeiensis), a vulnerable babbler endemic to southwestern China. Avian Res. 2016;7:18.

Ghalambor CK, Mckay JK, Carroll SP, Reznick DN. Adaptive versus nonadaptive phenotypic plasticity and the potential for contemporary adaptation in new environments. Funct Ecol. 2007:21:394-407.

Greenberg RG, Elphick C, Nordby JC, Gjerdrum C, Spautz H, Shriver G. Flooding and predation: trade-offs in the nesting ecology of tidal-marsh sparrows. Stud Avian Biol. 2006;32:96-109.

Hansell MH. Bird nests and construction behaviour. Cambridge: Cambridge University Press; 2000.

Hatchwell BJ, Russell AF, Fowlie MK, Ross DJ. Reproductive success and nest-site selection in a cooperative breeder: effect of experience and a direct benefit of helping. Auk. 1999;116:355-63.

Hildén O. Habitat selection in birds. Ann Zool Fenn. 1965;2:53-75.

Horvath $\mathrm{O}$. Seasonal differences in rufous hummingbird nest height and their relation to nest climate. Ecology. 1964;45:235-41.

Hunter EA. How will sea-level rise affect threats to nesting success for seaside sparrows? Condor. 2017;119:459-68.

Hunter EA, Nibbelink NP, Cooper RJ. Threat predictability influences seaside sparrow nest site selection when facing trade-offs from predation and flooding. Anim Behav. 2016;120:135-42.

Jakubas D. Factors affecting the breeding success of the grey heron (Ardea cinerea) in northern Poland. J Ornithol. 2005;146:27-33.

Jenouvrier S. Impacts of climate change on avian populations. Glob Change Biol. 2013;19:2036-57.

Jiang A, Jiang D, Zhou F, Goodale E. Nest-site selection and breeding ecology of streaked wren-babbler (Napothera brevicaudata) in a tropical limestone forest of southern China. Avian Res. 2017;8:28.

Jiguet F, Julliard R, Thomas CD, Dehorter O, Newson SE, Couvet D. Thermal range predicts bird population resilience to extreme high temperatures. Ecol Lett. 2006;9:1321-30.

Jones J. Habitat selection studies in avian ecology: a critical review. Auk. 2001;118:557-62.

Li D, Wei H, Sun X, Zhang Z. Nest-site selection of reed parrotbill in the mosaic reed harvesting habitats. Acta Ecol Sinica. 2015;35:5009-17.

Li D, Zhang Z, Grim T, Liang W, Stokke BG. Explaining variation in brood parasitism rates between potential host species with similar habitat requirements. Evol Ecol. 2016;30:905-23.

Ma L, Yang C, Liu J, Zhang J, Liang W, Møller AP. Costs of breeding far away from neighbors: isolated host nests are more vulnerable to cuckoo parasitism. Behav Process. 2018;157:327-32.

Macdonald EC, Camfield AF, Martin M, Wilson S, Martin K. Nest-site selection and consequences for nest survival among three sympatric songbirds in an alpine environment. J Ornithol. 2016;157:1-13. 
Maisey AC, Carter NT, Incoll JM, Bennett AF. Environmental influences on variation in nest-characteristics in a long-term study population of the superb lyrebird, Menura novaehollandiae. Emu. 2016;116:445-51.

Marshall RM, Reinert SE. Breeding ecology of seaside sparrows in a Massachusetts salt-marsh. Wilson Bull. 1990;102:501-13.

Martijn VDP, Ens BJ, Heg D, Brouwer L, Krol J, Maier M. Do changes in the frequency, magnitude and timing of extreme climatic events threaten the population viability of coastal birds? J Appl Ecol. 2010;47:720-30.

Martin TE. Nest predation and nest sites. Bioscience. 1993:43:523-32.

Martin TE. Avian life history evolution in relation to nest sites, nest predation, and food. Ecol Monogr. 1995;65:101-27.

Martin TE, Scott J, Menge C. Nest predation increases with parental activity: separating nest site and parental activity effects. Proc R Soc B: Biol Sci. 2000;267:2287-93.

Mérô TO, Žuljević A, Varga K, Lengyel S. Habitat use and nesting success of the great reed warbler (Acrocephalus arundinaceus) in different reed habitats in Serbia. Wilson J Ornithol. 2015;127:477-85.

Møller AP. Behavioral and life history responses to extreme climatic conditions: studies on a migratory songbird. Curr Zool. 2011;57:351-62.

Moreno J, Møller AP. Extreme climatic events in relation to global change and their impact on life histories. Curr Zool. 2011;57:375-89.

Murdoch WW. Switching in generalist predators: experiments on prey specificity and stability of prey populations. Ecol Monogr. 1969;39:335-54.
Palomino JJ, Martin-Vivaldi M, Soler M, Soler JJ. Functional significance of nest size variation in the rufous bush robin Cercotrichas galactotes. Ardea. 1998:86:177-85.

Piper SD, Catterall CP. Effects of edge type and nest height on predation of artificial nests within subtropical Australian eucalypt forests. Forest Ecol Manag. 2004;203:361-72.

Robertson BA, Hutto RL. A framework for understanding ecological traps and an evaluation of existing evidence. Ecology. 2006;87:1075-85.

Shisler BJ, Colony J. Nest site selection in laughing gulls in response to tidal flooding. Condor. 1980;82:249-56.

Sidle JG, Carlson DE, Kirsch EM, Dinan JJ. Flooding: mortality and habitat renewal for least terns and piping plovers. Colon Waterbirds. 1992:15:132-6.

Soler M. Long-term coevolution between avian brood parasites and their hosts. Biol Rev. 2014;89:688-704.

Vanderwerf EA. Evolution of nesting height in an endangered Hawaiian forest bird in response to a non-native predator. Conserv Biol. 2012;26:905-11.

Via S, Gomulkiewicz R, De JG, Scheiner SM, Schlichting CD, van Tienderen PH. Adaptive phenotypic plasticity: consensus and controversy. Trends Ecol Evol. 1995;10:212-7.

Yang C, Møller AP, Ma Z, Li F, Liang W. Intensive nest predation by crabs produces source-sink dynamics in hosts and parasites. J Ornithol. 2014;155:219-23.
Ready to submit your research? Choose BMC and benefit from:

- fast, convenient online submission

- thorough peer review by experienced researchers in your field

- rapid publication on acceptance

- support for research data, including large and complex data types

- gold Open Access which fosters wider collaboration and increased citations

- maximum visibility for your research: over 100M website views per year

At BMC, research is always in progress.

Learn more biomedcentral.com/submissions 